\title{
A Proper Increasing in the Testosterone Level May Be Associated With Better Pregnancy Outcomes for in Vitro Fertilization (IVF)/intracytoplasmic Sperm Injection (ICSI) Patients With Tubal or Male Infertility
}

\author{
Zhiyan Chen \\ Peking Union Medical College Hospital \\ Duoduo Zhang \\ Peking Union Medical College Hospital \\ Zhengyi Sun \\ Peking Union Medical College Hospital \\ Qi Yu ( $\square$ yuqi2008001@sina.com) \\ Peking union medical college hospital https://orcid.org/0000-0001-9737-5957
}

\section{Research}

Keywords: androgen, testosterone, in vitro fertilization (IVF)

Posted Date: April 13th, 2021

DOI: https://doi.org/10.21203/rs.3.rs-404854/v1

License: @ (1) This work is licensed under a Creative Commons Attribution 4.0 International License. Read Full License 


\section{Abstract \\ Background}

To investigate the relationship between androgen levels and pregnancy outcomes in patients with tubal or male infertility at different times of the in vitro fertilization (IVF)/intracytoplasmic sperm injection (ICSI) cycles.

\section{Methods}

Patients with tubal or male infertility but normal androgen levels receiving IVF/ICSI were continuously recruited. We made longitudinal analysis of the testosterone $(\mathrm{T}$ ) levels at three time points (T0: basal T levels, T1: T levels on the trigger day, T2: T levels on the next day of the trigger day) in three groups with different pregnancy outcomes (Group 1: no pregnancy, Group 2: clinical pregnancy but no live birth, Group 3: live birth) as repeated measurement data using linear mixed effect models. We also plotted fitting curves depicting the relationship of the T levels and the numbers of oocytes retrieved at different time points, and the inflection points of the curves were identified.

\section{Results}

A total of 3012 patients were recruited in the study. Improvements in androgen levels were identified at the three-time points in Group 1 and 3. The slope in Group 3 after refitting was significantly higher than Group $1(P=0.000)$. The curves that reflected the association of androgen levels and numbers of retrieved oocytes presented an upward trend before a certain inflection point, after which the curves had no obvious changes or fell with the increase of androgen levels. The inflection points for T0, T1, T2 were calculated as $0.45,0.94,1.09$, respectively.

\section{Conclusion}

The faster upward trend of the T levels might be associated with better pregnancy outcomes. Within the range of lower than a certain value of the T levels, more oocytes and embryos could be obtained with the increasing of the T levels.

\section{Background}

Androgens, a category of sex steroid hormones, play an essential role in women's endocrine and reproductive systems. For females, the androgens that can be detected in blood circulation are testosterone $(\mathrm{T})$ [1], dihydrotestosterone (DHT), and pro-androgens, including dehydroepiandrosterone sulfate (DHEAS), dehydroepiandrosterone (DHEA), androstenedione (A4). Androgens activate and exert effects on sensitive tissues via the androgen receptor (AR) of women, and T serves as the precursor for estradiol (E2) production[2]. In recent years, the physiology of androgen in women, which presents complex effects on fertility, and its utilization in Assisted Reproductive Technology (ART), has triggered interest from gynecologists [3].

There are accumulating evidences from basic discovery research, clinical trials and meta-analysis supporting that androgens may have a synergistic stimulatory role with FSH in early follicle growth, maintenance of follicle health and maturity of the follicles during the later stages of development [4].

The androgen levels, including T and DHEA, decline gradually with age among the women of 25-40 years old [5]. The addition of T or DHEA for the women with poor respondence to recombinant follicle stimulating hormone (FSH)-induced ovarian stimulation in the IVF process has been undertaken by medical centers broadly [6]. On the other hand, high levels of androgens can prevent follicle maturation and harm follicle development. Hyperandrogenism, such as polycystic ovarian syndrome (PCOS) and congenital adrenal hyperplasia, constitutes a significant cause of female infertility [7]. Studies have supported that androgen excess has a detrimental impact on infertility [8]. And excessive androgens can cause hyper-recruitment of follicles in the ovaries, leading to impaired maturation and infertility [9]. As the effect of androgens on follicle maturation and pregnancy outcome varies with their levels, it is of clinical value to evaluate the association of androgens and IVF outcomes. According to previous studies, the basal T levels might be related to ovarian responding competence and IVF outcomes. Still, the androgen levels in different time points of IVF cycles have not 
been reported yet. Therefore, in this study, We investigated the relationship between androgen levels and pregnancy outcomes in patients with tubal or male infertility at different times of the IVF/intracytoplasmic sperm injection (ICSI) cycles. By exploring the changes of androgen levels during the stimulation cycle, we aim to find optimized androgen levels in ovarian stimulation cycles and provide clinical evidence for adding androgens for patients with poor ovarian response (POR) during IVF process. We also expect to provide appropriate target values for androgen-lowering regimens before IVF in infertile patients with combined hyperandrogenism.

\section{Methods}

\section{Participants recruitment}

The institutional review board approved the retrospective observational study of Peking Medical College Hospital (No. S-K601). From 2014 July to 2018 March, patients with tubal or male infertility but normal androgen levels receiving IVF/ICSI in Peking Medical College Hospital were continuously recruited in the study. Written informed consent was received by the patients. Patients with hyperandrogenism, including PCOS and congenital adrenal hyperplasia, were excluded from the study. Other exclusion criteria were endometriosis, other endocrine disorders, such as diabetes, pituitary dysfunction, thyroid diseases, and malignancy history. All of the patients underwent IVF/ICSI with a gonadotropin-releasing hormone agonist (GnRHa) long protocol.

\section{Baseline clinical characteristics and hormonal assays}

The clinical characteristics of each patient at the IVF baseline were recorded, including age, body mass index (BMI), and duration of infertility.

At three-time points during the IVF/ICSI cycles, the T levels were regarded as the main variables for analysis. The three-time points for testing the T level were listed as follows. Firstly, we tested the T levels on the 2 nd day of menstruation before controlled ovarian hyperstimulation $(\mathrm{COH})$ as the baseline values, marked as $\mathrm{T} 0$. The second testing of $\mathrm{T}$ levels was set on the trigger day receiving human chorionic gonadotropin (hCG) for final oocyte maturation, marked as T1. The third testing, marked as T2, was performed on the following day after hCG injection.

The baseline hormone profiles, including human FSH, E2, luteinizing hormone (LH), prolactin (PRL), were tested on the $2 n d$ day of the menstrual cycle.

The hormones' serum levels were measured by electrochemiluminescent immunoassay (automated Elecsys Immunoanalyzer, Beckmann, USA). The mean interassay coefficients of variation (CVs) were $<5 \%$ for $\mathrm{T},<5 \%$ for E2, and $<8 \%$ for FSH, LH, and PRL.

\section{confirmation of the fertility outcomes}

The numbers of oocytes retrieved, clinical pregnancy rate, and live birth rate were referred to as the primary analysis outcomes. The definition of clinical pregnancy was the validation of the gestational sac and fetal heart by transvaginal ultrasound. Live birth was defined as an infant born alive after 28 gestational weeks. The cumulated outcomes within all of the stimulating cycles of individual patients were evaluated in determining clinical pregnancy and live birth. For those patients who chose freeze-all strategy after oocytes retrieval due to various reasons, such as ovarian hyperstimulation syndrome risk and inflammation, the cryopreserved blastocysts were thawed and transplanted subsequently. And the cumulative live birth rate was assessed. The secondary outcomes included the numbers of metaphase II (MII) oocytes, numbers of two-pronuclear zygotes, numbers of cleavage-stage embryos, numbers of the top quality embryos on the 3rd day (TQE[D3]), and numbers of blastocyst-stage embryos.

\section{statistical analysis}

Continuous variables are described as mean \pm standard deviation (SD), and categorical variables are expressed as percentages (\%). The student's t-test was used for comparing the continuous variables, and Fisher's exact test was used for categorical variables.

Firstly, we made longitudinal analysis of testosterone within the cycle as repeated measurement data. Due to the repeated measurement data's within-participant correlation, linear mixed effect models were constructed using random intercept random slope 
models for analyzing the repeated measurement data. The restricted maximum likelihood (MLE) method was used to refit the models to a straight line and calculate the regression estimates and the $95 \%$ confidence intervals (Cls) of linear mixed effect models.

We plotted smooth fitting curves showing the relationship of the testosterone levels and numbers of oocytes retrieved at different time points using the method of generalized additive models (GAM)-based spline smoothing, with adjusting other possible related factors.

To further identify the fitting curves' inflection points, the MLE method was applied, presented as the value of testosterone level. And $\beta$ coefficients of the two segments before and after the inflection point were calculated as the effect-size metric. The differences in slopes between the two segments were evaluated using the Wald test.

The statistical analysis was performed using R (http://www.R-project. org) and EmpowerStats software (X\&Y Solutions). p values < 0.05 were considered statistically significant.

\section{Results}

\section{Patients characteristics and Hormonal testing}

A total of 3012 patients undergoing IVF/ICSI were recruited in the study. The patients' mean age was $34.9 \pm 4.3$, and a total of 2101 patients received IVF cycles, and 911 had ICSI. The study flow is shown in Fig. 1. We divided the patients into three groups according to the pregnancy outcomes: Group 1: no clinical pregnancy, Group 2: clinical pregnancy but no live birth, Group 3: live birth. The clinical characteristics of the patients in the three groups are demonstrated in Table 1.

Table 1

Baseline characteristics of participants

\begin{tabular}{|c|c|c|c|c|}
\hline & G1: No clinical pregnancy & G2: Clinical pregnancy & G3: Live birth & P-value \\
\hline $\mathrm{N}$ & 1427 & 204 & 1381 & \\
\hline Age (years) & $35.33 \pm 4.51$ & $35.26 \pm 4.10$ & $34.43 \pm 4.13$ & $<0.001$ \\
\hline $\mathrm{BMI}\left(\mathrm{kg} / \mathrm{m}^{2}\right)$ & $21.98 \pm 3.18$ & $22.40 \pm 3.32$ & $22.16 \pm 3.11$ & 0.102 \\
\hline Duration of infertility (years) & $4.82 \pm 3.26$ & $5.05 \pm 3.43$ & $4.56 \pm 2.79$ & 0.025 \\
\hline Method & & & & 0.389 \\
\hline IVF & $991(69.45 \%)$ & $151(74.02 \%)$ & $959(69.44 \%)$ & \\
\hline ICSI & $436(30.55 \%)$ & $53(25.98 \%)$ & $422(30.56 \%)$ & \\
\hline Basal FSH (IU/L) & $8.18 \pm 4.03$ & $7.74 \pm 3.08$ & $7.60 \pm 3.33$ & $<0.001$ \\
\hline Basal LH (IU/L) & $4.40 \pm 3.55$ & $4.12 \pm 2.11$ & $4.21 \pm 2.67$ & 0.166 \\
\hline Basal PRL (ng/mL) & $17.92 \pm 9.50$ & $18.63 \pm 10.19$ & $17.82 \pm 8.62$ & 0.503 \\
\hline Basal E2 (pg/mL) & $50.66 \pm 31.17$ & $49.93 \pm 25.82$ & $51.55 \pm 34.40$ & 0.675 \\
\hline Basal T (ng/mL) & $0.48 \pm 0.78$ & $0.56 \pm 1.49$ & $0.45 \pm 0.43$ & 0.104 \\
\hline
\end{tabular}

\section{Longitudinal analysis of the repeated Measurement of androgen levels at the threetime points}

The changes of androgen levels of the three groups at baseline, the trigger day receiving hCG, and the next day of hCG uptake, are illustrated in Fig. 2. And Table 2 describes the results of comparing the androgen levels at different time points. For Group 1 and 3 , the lines presented an overall upward trend, and there exhibited improvements in androgen levels with time (Group 1: P[T1-T0] = $0.000, P[T 2-T 0]=0.0001$; Group 3: P[T1-T0] = 0.000, P[T2-T0] = 0.000). The slope of T0-T2 in Group 3 after refitting by the MLE method was significantly higher than Group $1(P=0.000)$, indicating that the upward trend of androgen levels in live birth were significantly faster than that of no clinical pregnancy. 
Table 2

Repeated measurement analysis of androgen levels at three time points with different IVF outcomes using linear mixed effect models

\begin{tabular}{|c|c|c|c|c|c|c|c|c|c|c|}
\hline & \multirow{2}{*}{$\begin{array}{l}\text { Androgen } \\
\text { level of } \\
\text { T0 } \\
(\mathrm{ng} / \mathrm{mL})\end{array}$} & \multirow{2}{*}{$\begin{array}{l}\text { Androgen } \\
\text { level of } \\
\text { T1 } \\
\text { (ng/mL) }\end{array}$} & \multirow{2}{*}{$\begin{array}{l}\text { Androgen } \\
\text { level of } \\
\text { T2 } \\
(\mathrm{ng} / \mathrm{mL})\end{array}$} & \multirow[t]{2}{*}{$P^{*}$} & \multicolumn{2}{|l|}{ T1-T0 } & \multicolumn{2}{|l|}{ T2-T0 } & \multicolumn{2}{|l|}{ Refitting } \\
\hline & & & & & $\mathrm{B}^{\mathrm{a}}$ & $\mathbf{P}$ & $\mathrm{B}^{\mathrm{b}}$ & $\mathbf{P}$ & $\mathrm{B}^{\mathrm{C}}$ & $P$ \\
\hline $\begin{array}{l}\text { G1 } \\
(n=1427)\end{array}$ & $\begin{array}{l}0.48 \pm \\
0.78\end{array}$ & $\begin{array}{l}0.60 \pm \\
0.25\end{array}$ & $\begin{array}{l}0.72 \pm \\
0.38\end{array}$ & 0.104 & $\begin{array}{l}0.0664 \\
\pm \\
0.0165\end{array}$ & 0.000 & $\begin{array}{l}0.175 \\
\pm \\
0.0165\end{array}$ & 0.000 & / & / \\
\hline $\begin{array}{l}\text { G2ssssssssssssssss } \\
(n=204)\end{array}$ & $\begin{array}{l}0.56 \pm \\
1.49\end{array}$ & $\begin{array}{l}0.58 \pm \\
0.24\end{array}$ & $\begin{array}{l}0.71 \pm \\
0.28\end{array}$ & 0.644 & $\begin{array}{l}0.0626 \\
\pm \\
0.0467\end{array}$ & 0.179 & $\begin{array}{l}0.0773 \\
\pm \\
0.0467\end{array}$ & 0.098 & $\begin{array}{l}0.0270 \\
\pm \\
0.0241\end{array}$ & 0.262 \\
\hline $\begin{array}{l}\text { G3 } \\
(n=1381)\end{array}$ & $\begin{array}{l}0.45 \pm \\
0.43\end{array}$ & $\begin{array}{l}0.60 \pm \\
0.23\end{array}$ & $\begin{array}{l}0.73 \pm \\
0.33\end{array}$ & 0.674 & $\begin{array}{l}0.129 \\
\pm \\
0.0234\end{array}$ & 0.000 & $\begin{array}{l}0.159 \\
\pm \\
0.0234\end{array}$ & 0.000 & $\begin{array}{l}0.0542 \\
\pm \\
0.0121\end{array}$ & 0.000 \\
\hline
\end{tabular}

*: $\mathrm{P}$ value of comparing androgen levels at three time points

a: Regression estimate of T1-T0 changes, values in bold have statistical significance

b: Regression estimate of T2-T0 changes, values in bold have statistical significance

C: Regression estimate of comparing the refitting lines of $\mathrm{G} 1$ with $\mathrm{G} 0$, and $\mathrm{G} 2$ with $\mathrm{G} 0$, values in bold have statistical significance

T0: basal levels, T1: T levels on the trigger day, T2: T levels on the next day of the trigger day

\section{Fitting curves of the relationship between androgen levels and pregnancy outcomes}

We plotted the three fitting curves to illustrate the association of androgen levels and numbers of retrieved oocytes at the three-time points (T0, T1, T2) (Fig. 3). In the beginning, all the curves presented an upward trend, and after a certain inflection point, the curves had no obvious changes or fell with the increase of androgen levels. The inflection points for T0, T1, T2 were calculated as $0.45,0.94$, 1.09 , respectively. The differences in the slopes before and after the inflection points were statistically significant for the three curves $(\mathbf{P}(\mathrm{T0})=0.0480, \mathbf{P}(\mathrm{T} 1)<0.0001, \mathrm{P}(\mathrm{T} 2)<0.0001)$ (Table 3 ). According to the results above, we can conclude that at the baseline, the numbers of retrieved oocytes increase with androgen levels when the androgen level is $<0.45 \mathrm{ng} / \mathrm{mL}$ and are not associated with the androgen levels when $>0.45 \mathrm{ng} / \mathrm{mL}$. On the trigger day, the numbers of retrieved oocytes increase with androgen levels when the androgen level is $<0.94 \mathrm{ng} / \mathrm{mL}$ and are not associated with the androgen levels when $>0.94 \mathrm{ng} / \mathrm{mL}$. And for the next day of receiving hCG, the value of androgen level is 1.07 when the numbers of retrieved oocytes start to decline with increasing androgens. The comparisons of pregnancy outcomes between patients with T levels lower than and higher than the inflection point at the three time points are shown in Table 4. Significant differences were detected in the secondary outcome variables, indicating that the $T$ levels higher than the inflection point at the three time points were associated with more acquired oocytes and embryos. (The fitting curves and inflection points calculation of $\mathrm{T}$ levels and other outcomes are affiliated in Supplementary materials.) 
Table 3

The analysis of the inflection points and the effect sizes of the curves reflecting the association of $T$ levels and numbers of oocytes retrieved

\begin{tabular}{|llll|}
\hline & T0 & T1 & T2 \\
\hline Inflection point $(\mathrm{K})(\mathrm{ng} / \mathrm{mL})$ & 0.45 & 0.94 & 1.09 \\
\hline$\beta 1(95 \% \mathrm{Cl})<\mathrm{k}^{*}$ & $1.91(0.09,3.74)$ & $8.91(7.99,9.82)$ & $9.71(9.00,10.43)$ \\
\hline $\mathrm{P}(\beta 1)$ & 0.0396 & $<0.0001$ & $<0.0001$ \\
\hline$\beta 2(95 \% \mathrm{Cl})>\mathrm{k}^{* *}$ & $0.03(-0.20,0.27)$ & $-0.29(-2.69,2.11)$ & $-1.42(-2.05,-0.79)$ \\
\hline $\mathrm{P}(\beta 2)$ & 0.7808 & 0.8125 & $<0.0001$ \\
\hline Difference for $(\beta 2-\beta 1)$ & $-1.88(-3.75,-0.02)$ & $-9.20(-12.05,-6.34)$ & $-11.13(-12.19,-10.07)$ \\
\hline$P(\beta 2-\beta 1)$ & 0.0480 & $<0.0001$ & $<0.0001$ \\
\hline$*: \beta$ coefficient of the section before the inflection point & \\
\hline$* *: \beta$ coefficient of the section after the inflection point & \\
\hline T0: basal levels, $T 1$ : $T$ levels on the trigger day, T2: T levels on the next day of the trigger day \\
\hline
\end{tabular}

Table 4

Comparisons of pregnancy outcomes between patients with $\mathrm{T}$ levels $\leq$ and $>$ the inflection point at the three time points

\begin{tabular}{|c|c|c|c|c|c|c|c|c|c|}
\hline & TO & & & $\mathrm{T} 1$ & & & $\mathrm{~T} 2$ & & \\
\hline Testosterone (ng/mL) & $\leq 0.45$ & $>0.45$ & $\mathrm{P}$ & $\leq 0.94$ & $>0.94$ & $\mathrm{P}$ & $\leq 1.09$ & $>1.09$ & $\mathrm{P}$ \\
\hline $\mathrm{N}$ & 1809 & 1195 & & 2761 & 251 & & 2704 & 308 & \\
\hline No. of oocytes retrieved & $\begin{array}{l}8.22 \pm \\
4.97\end{array}$ & $\begin{array}{l}8.87 \pm \\
5.15\end{array}$ & $<.001$ & $\begin{array}{l}8.17 \pm \\
4.92\end{array}$ & $\begin{array}{l}11.96 \pm \\
5.08\end{array}$ & $<.001$ & $\begin{array}{l}8.06 \pm \\
4.87\end{array}$ & $\begin{array}{l}12.21 \pm \\
5.04\end{array}$ & $\begin{array}{l}< \\
0.001\end{array}$ \\
\hline No. of MIl oocytes & $\begin{array}{l}7.04 \pm \\
4.71\end{array}$ & $\begin{array}{l}7.65 \pm \\
4.87\end{array}$ & $\begin{array}{l}< \\
0.001\end{array}$ & $\begin{array}{l}7.00 \pm \\
4.64\end{array}$ & $\begin{array}{l}10.39 \pm \\
5.10\end{array}$ & $<.001$ & $\begin{array}{l}6.90 \pm \\
4.58\end{array}$ & $\begin{array}{l}10.61 \pm \\
5.12\end{array}$ & $\begin{array}{l}< \\
0.001\end{array}$ \\
\hline $\begin{array}{l}\text { No. of two-pronuclear } \\
\text { zygotes }\end{array}$ & $\begin{array}{l}6.35 \pm \\
4.65\end{array}$ & $\begin{array}{l}6.88 \pm \\
4.81\end{array}$ & $<0.001$ & $\begin{array}{l}6.31 \pm \\
4.58\end{array}$ & $\begin{array}{l}9.36 \pm \\
5.26\end{array}$ & $<0.001$ & $\begin{array}{l}6.23 \pm \\
4.52\end{array}$ & $\begin{array}{l}9.50 \pm \\
5.36\end{array}$ & $\begin{array}{l}< \\
0.001\end{array}$ \\
\hline $\begin{array}{l}\text { No. of cleavage-stage } \\
\text { embryos }\end{array}$ & $\begin{array}{l}6.31 \pm \\
4.66\end{array}$ & $\begin{array}{l}6.86 \pm \\
4.82\end{array}$ & $<001$ & $\begin{array}{l}6.27 \pm \\
4.60\end{array}$ & $\begin{array}{l}9.36 \pm \\
5.25\end{array}$ & $<001$ & $\begin{array}{l}6.19 \pm \\
4.53\end{array}$ & $\begin{array}{l}9.49 \pm \\
5.36\end{array}$ & $\begin{array}{l}< \\
0.001\end{array}$ \\
\hline No. of TQE on the 3rd day & $\begin{array}{l}0.81 \pm \\
1.27\end{array}$ & $\begin{array}{l}0.84 \pm \\
1.23\end{array}$ & 0.463 & $\begin{array}{l}0.80 \pm \\
1.24\end{array}$ & $\begin{array}{l}1.10 \pm \\
1.37\end{array}$ & $<001$ & $\begin{array}{l}0.77 \pm \\
1.22\end{array}$ & $\begin{array}{l}1.25 \pm \\
1.50\end{array}$ & $\begin{array}{l}< \\
0.001\end{array}$ \\
\hline $\begin{array}{l}\text { No. of blastocyst-stage } \\
\text { embryos }\end{array}$ & $\begin{array}{l}1.66 \pm \\
2.54\end{array}$ & $\begin{array}{l}1.95 \pm \\
2.68\end{array}$ & $\begin{array}{l}< \\
0.001\end{array}$ & $\begin{array}{l}1.65 \pm \\
2.50\end{array}$ & $\begin{array}{l}3.12 \pm \\
3.22\end{array}$ & $<001$ & $\begin{array}{l}1.61 \pm \\
2.45\end{array}$ & $\begin{array}{l}3.21 \pm \\
3.31\end{array}$ & $\begin{array}{l}< \\
0.001\end{array}$ \\
\hline \multicolumn{10}{|l|}{$\mathrm{T}$ : testosterone } \\
\hline \multicolumn{10}{|l|}{ MII: Metaphase II } \\
\hline \multicolumn{10}{|l|}{ TQE: top quality embryo } \\
\hline T0: basal levels, T1: T leve & 7 the tr & day, T? & vels of & e next & f thet & & & & \\
\hline
\end{tabular}

\section{Discussion}

In this study, we found that for the patients with tubal or male infertility who underwent IVF/ICSI, the cumulative live birth rate was higher in those patients who had faster androgen level upward trend from the baseline to the trigger day. By examining the relationship between androgen level changes and the numbers of oocytes retrieved, we found that the highest level of oocyte retrival rates can be acquired when the androgen levels reached $0.45 \mathrm{ng} / \mathrm{mL}$ on the baseline, $0.94 \mathrm{ng} / \mathrm{mL}$ on the trigger day, and $1.09 \mathrm{ng} / \mathrm{mL}$ 
on the second day of the hCG administration. We, therefore, hypothesized that a proper increase in androgen levels during the ovarian hyperstimulation might increase the number of retrieved oocytes and have a positive impact on the IVF outcomes.

In normal females, androgens are a category of essential hormones that are highly involved in the promotion of follicular development through enhancing follicle recruitment and growth [10], as well as increasing insulin like growth factor 1 (IGF-1) expression in the ovary [11]. It has also been revealed by some animal studies that androgens benefit follicular development through their promoting effects on preantral and small antral follicles in a dose-dependent manner $[12,13]$. There is also clinical evidence indicating that androgen levels are positively correlated with ovarian response and may predict IVF outcomes [14, 15]. On the other hand, over-expressed androgens, in patients with PCOS and other hyperandrogenic diseases, can generate adverse effects on the preovulatory follicles, leading to anovulation and infertility subsequently [16, 17]. In terms of the double-edged impact of androgens on follicle development and women's fertility, androgens are also likely to play a role in the success rate of IVF. With the increasing use of androgens pre-treatment to improve ovarian response to hyperstimulation in patients with POR, a comprehensive assessment of androgens' role in IVF-receiving women is in need.

POR is one of the major causes that contribute to IVF failure. The addition of exogenous androgens or androgen-modulating agents for the POR patients receiving IVF has been broadly utilized in the clinical[18]. Recent studies have also been focusing on the pretreatment effect of androgens for POR patients before receiving IVF. However, contradictory results were reported that some studies confirmed the efficacy of androgens in enhancing live birth rate [19-21], and some negated the conclusion [19, 22]. This could be partly accounted for by the differences in study populations and timing and duration of androgens pre-treatment. Also, the changes of androgen levels after the addition of androgens and the association between the androgen changes and IVF outcomes were not explored.

For the women receiving IVF without endocrine abnormalities, the role of androgen levels in predicting IVF outcomes has not been established yet. One study about the basal T levels in women with usual ovarian reserve indicated that the low $T$ level might be relevant to the inadequate ovarian response in IVF [23]. It was also suggested by John L et al. that the T level $\leq 20 \mathrm{ng} / \mathrm{dL} \mathrm{might}$ be correlated with poor IVF outcomes, but other studies denied the predictive role of $\mathrm{T}$ [24, 25]. In these studies, the changes in androgen levels were not discussed, either.

To our knowledge, our study is the first to explore the relationship between androgen changes at different time points of IVF cycles and IVF outcomes. In this study, we found that patients with a faster change in androgen levels from baseline to trigger day were more likely to achieve good IVF outcomes. Our study may also explain the differential treatment efficacy of androgen pre-treatment in POR patients, as the changes in androgen levels might influence the outcomes. We plan to investigate androgen changes with pregnancy outcomes for the patients receiving androgen pre-treatment before IVF through further prospective cohort studies. Besides, based on this study's results, a reference goal of androgen reduction before undertaking IVF for the patients with hyperandrogenism could be obtained.

There still exist several limitations in the study. Firstly, as a retrospective study, selection bias and recall bias were inevitable, we minimized the recall bias since all the data were recorded and extracted in the computerized database. And some confounding factors, such as age, BMI, and years of infertility, have been adjusted. Secondly, our study is a single-center study with a limited number of patients and IVF cycles. In future studies, the sample size will be enlarged to authenticate the conclusions further. Finally, we excluded the patients with hyperandrogenism and mainly focused on the patients with tubal or male infertility. Studies about the androgen changes in patients with endocrine disorders are in need.

In conclusion, in this study, by exploring the changes of T levels with time points of IVF/ICSI cycles, we found that the faster upward trend of the $T$ levels might be associated with better pregnancy outcomes. Besides, the pregnancy outcomes are positively associated with the $T$ levels within a certain range of the $T$ levels. A proper increase of $T$ levels might be beneficial to enhance the ovarian responses and IVF outcomes.

\section{Abbreviations}

In vitro fertilization (IVF)

Intracytoplasmic sperm injection (ICSI)

Page $7 / 12$ 
Testosterone ( $\mathrm{T}$ )

Dihydrotestosterone (DHT)

Dehydroepiandrosterone sulfate (DHEAS),

Dehydroepiandrosterone (DHEA)

Androstenedione (A4)

Androgen receptor (AR)

Estradiol (E2)

Assisted Reproductive Technology (ART)

Follicle-stimulating hormone (FSH)

polycystic ovarian syndrome (PCOS)

poor ovarian response (POR)

gonadotropin-releasing hormone agonist ( $\mathrm{GnRHa}$ )

body mass index (BMI)

controlled ovarian hyperstimulation $(\mathrm{COH})$

human chorionic gonadotropin (hCG)

luteinizing hormone (LH)

prolactin (PRL)

coefficients of variation (CVs)

metaphase II (MII)

top quality embryos on the 3rd day (TQE[D3])

standard deviation (SD)

maximum likelihood (MLE)

confidence intervals (Cls)

generalized additive models (GAM)

\section{Declarations}

Ethics approval and consent to participate: The institutional review board approved the retrospective observational study of Peking Medical College Hospital (No. S-K601). Written informed consent was received by the patients.

Availability of data and materials: The datasets used and/or analysed during the current study are available from the corresponding author on reasonable request.

Competing interests: The authors declare no conflict interests.

Funding: the National Key Research and Development Program (2018YFC1002105). 
Authors' contributions: DZ collected and validated the patient data. ZC analyzed and interpreted the patient data, and was a major contributor in writing the manuscript. ZS and QY supervised the study and revised the manuscript. All authors read and approved the final manuscript.

Acknowledgements: NA.

\section{References}

1. Gougeon A: Regulation of ovarian follicular development in primates: facts and hypotheses. Endocr Rev 1996, 17:121-155.

2. Simpson ER, Clyne C, Rubin G, Boon WC, Robertson K, Britt K, Speed C, Jones M: Aromatase-a brief overview. Annu Rev Physiol 2002, 64:93-127.

3. Simpson E, Rubin G, Clyne C, Robertson K, O'Donnell L, Jones M, Davis S: The role of local estrogen biosynthesis in males and females. Trends Endocrinol Metab 2000, 11:184-188.

4. Meldrum DR, Chang RJ, Giudice LC, Balasch J, Barbieri RL: Role of decreased androgens in the ovarian response to stimulation in older women. Fertil Steril 2013, 99:5-11.

5. Davison SL, Bell R, Montalto JG, Sikaris K, Donath S, Stanczyk FZ, Davis SR: Measurement of total testosterone in women: comparison of a direct radioimmunoassay versus radioimmunoassay after organic solvent extraction and celite column partition chromatography. Fertil Steril 2005, 84:1698-1704.

6. Gleicher N, Barad DH: Dehydroepiandrosterone (DHEA) supplementation in diminished ovarian reserve (DOR). Reprod Biol Endocrinol 2011, 9:67.

7. Dumesic DA, Oberfield SE, Stener-Victorin E, Marshall JC, Laven JS, Legro RS: Scientific Statement on the Diagnostic Criteria, Epidemiology, Pathophysiology, and Molecular Genetics of Polycystic Ovary Syndrome. Endocr Rev 2015, 36:487-525.

8. Mannerås L, Cajander S, Holmäng A, Seleskovic Z, Lystig T, Lönn M, Stener-Victorin E: A new rat model exhibiting both ovarian and metabolic characteristics of polycystic ovary syndrome. Endocrinology 2007, 148:3781-3791.

9. Walters KA, Rodriguez Paris V, Aflatounian A, Handelsman DJ: Androgens and ovarian function: translation from basic discovery research to clinical impact. J Endocrinol 2019, 242:R23-r50.

10. Vendola KA, Zhou J, Adesanya 00, Weil SJ, Bondy CA: Androgens stimulate early stages of follicular growth in the primate ovary. J Clin Invest 1998, 101:2622-2629.

11. Vendola K, Zhou J, Wang J, Bondy CA: Androgens promote insulin-like growth factor-I and insulin-like growth factor-I receptor gene expression in the primate ovary. Hum Reprod 1999, 14:2328-2332.

12. Shorakae S, Boyle J, Teede H: Polycystic ovary syndrome: a common hormonal condition with major metabolic sequelae that physicians should know about. Intern Med J 2014, 44:720-726.

13. Lebbe M, Taylor AE, Visser JA, Kirkman-Brown JC, Woodruff TK, Arlt W: The Steroid Metabolome in the Isolated Ovarian Follicle and Its Response to Androgen Exposure and Antagonism. Endocrinology 2017, 158:1474-1485.

14. Sun B, Wang F, Sun J, Yu W, Sun Y: Basal serum testosterone levels correlate with ovarian response but do not predict pregnancy outcome in non-PCOS women undergoing IVF. J Assist Reprod Genet 2014, 31:829-835.

15. Luo S, Li S, Li X, Qin L, Jin S: Effect of pretreatment with transdermal testosterone on poor ovarian responders undergoing IVF/ICSI: A meta-analysis. Exp Ther Med 2014, 8:187-194.

16. Dilaver N, Pellatt L, Jameson E, Ogunjimi M, Bano G, Homburg R, H DM, Rice S: The regulation and signalling of anti-Müllerian hormone in human granulosa cells: relevance to polycystic ovary syndrome. Hum Reprod 2019, 34:2467-2479.

17. Owens LA, Kristensen SG, Lerner A, Christopoulos G, Lavery S, Hanyaloglu AC, Hardy K, Yding Andersen C, Franks S: Gene Expression in Granulosa Cells From Small Antral Follicles From Women With or Without Polycystic Ovaries. J Clin Endocrinol Metab 2019, 104:6182-6192.

18. Montoya-Botero P, Rodriguez-Purata J, Polyzos NP: Androgen supplementation in assisted reproduction: where are we in 2019 ? Curr Opin Obstet Gynecol 2019, 31:188-194.

19. Bosdou JK, Venetis CA, Dafopoulos K, Zepiridis L, Chatzimeletiou K, Anifandis G, Mitsoli A, Makedos A, Messinis IE, Tarlatzis BC, Kolibianakis EM: Transdermal testosterone pretreatment in poor responders undergoing ICSI: a randomized clinical trial. Hum Reprod 2016, 31:977-985. 
20. Doan HT, Quan LH, Nguyen TT: The effectiveness of transdermal testosterone gel 1\% (androgel) for poor responders undergoing in vitro fertilization. Gynecol Endocrinol 2017, 33:977-979.

21. Saharkhiz N, Zademodares S, Salehpour S, Hosseini S, Nazari L, Tehrani HG: The effect of testosterone gel on fertility outcomes in women with a poor response in in vitro fertilization cycles: A pilot randomized clinical trial. J Res Med Sci 2018, 23:3.

22. Sipe CS, Thomas MR, Stegmann BJ, Van Voorhis BJ: Effects of exogenous testosterone supplementation in gonadotrophin stimulated cycles. Hum Reprod 2010, 25:690-696.

23. Qin Y, Zhao Z, Sun M, Geng L, Che L, Chen ZJ: Association of basal serum testosterone levels with ovarian response and in vitro fertilization outcome. Reprod Biol Endocrinol 2011, 9:9.

24. Barbieri RL, Sluss PM, Powers RD, McShane PM, Vitonis A, Ginsburg E, Cramer DC: Association of body mass index, age, and cigarette smoking with serum testosterone levels in cycling women undergoing in vitro fertilization. Fertil Steril 2005, 83:302-308.

25. Walters KA, Allan CM, Handelsman DJ: Androgen actions and the ovary. Biol Reprod 2008, 78:380-389.

\section{Figures}

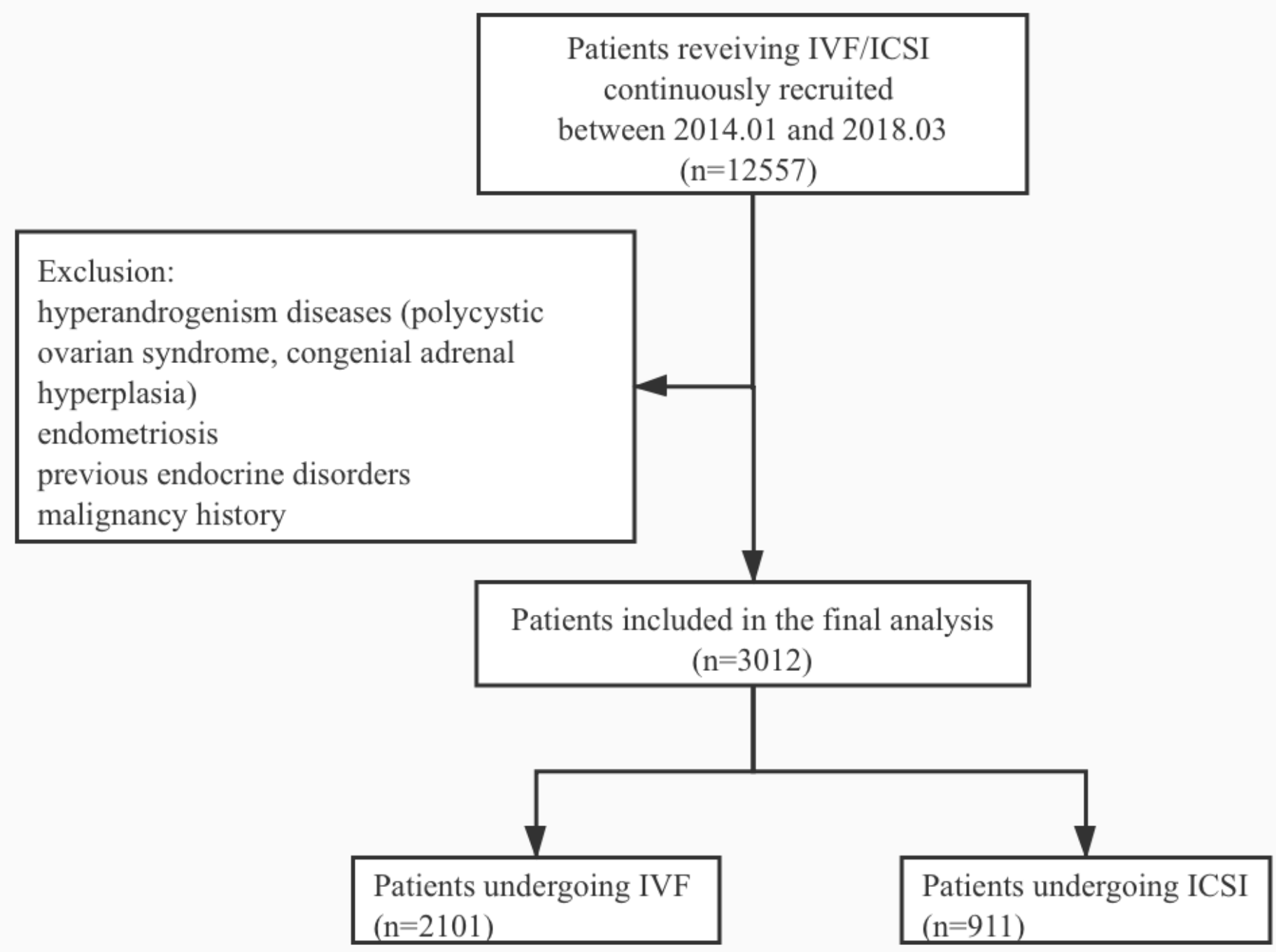

Figure 1

The schematic of study flow 


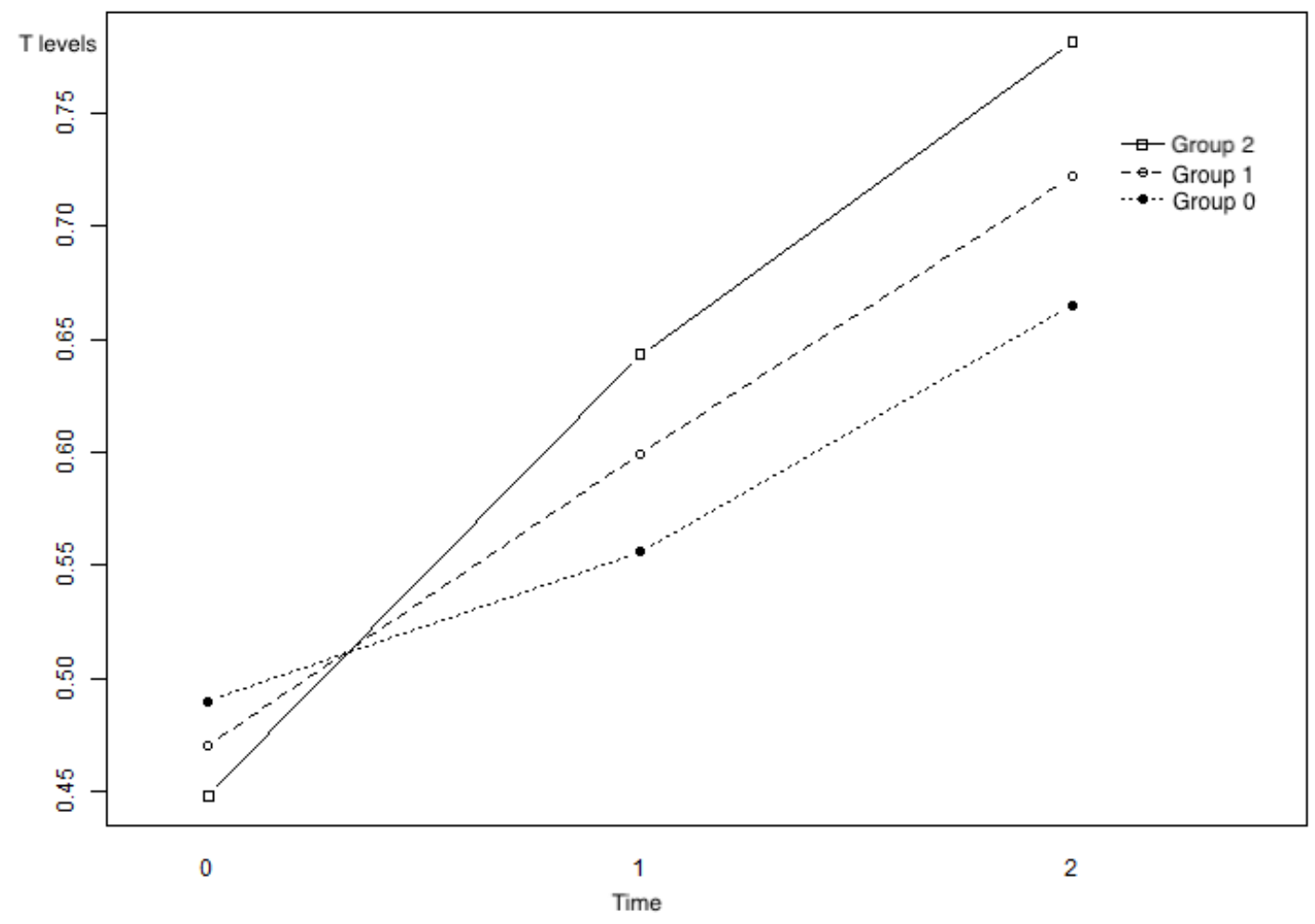

Figure 2

The changes of the testosterone levels of Group 1-3. Group 1: no clinical pregnancy; Group 2: clinical pregnancy and no live birth; Group 3: live birth. T0: basal levels, T1: T levels on the trigger day, T2: T levels on the next day of the trigger day 

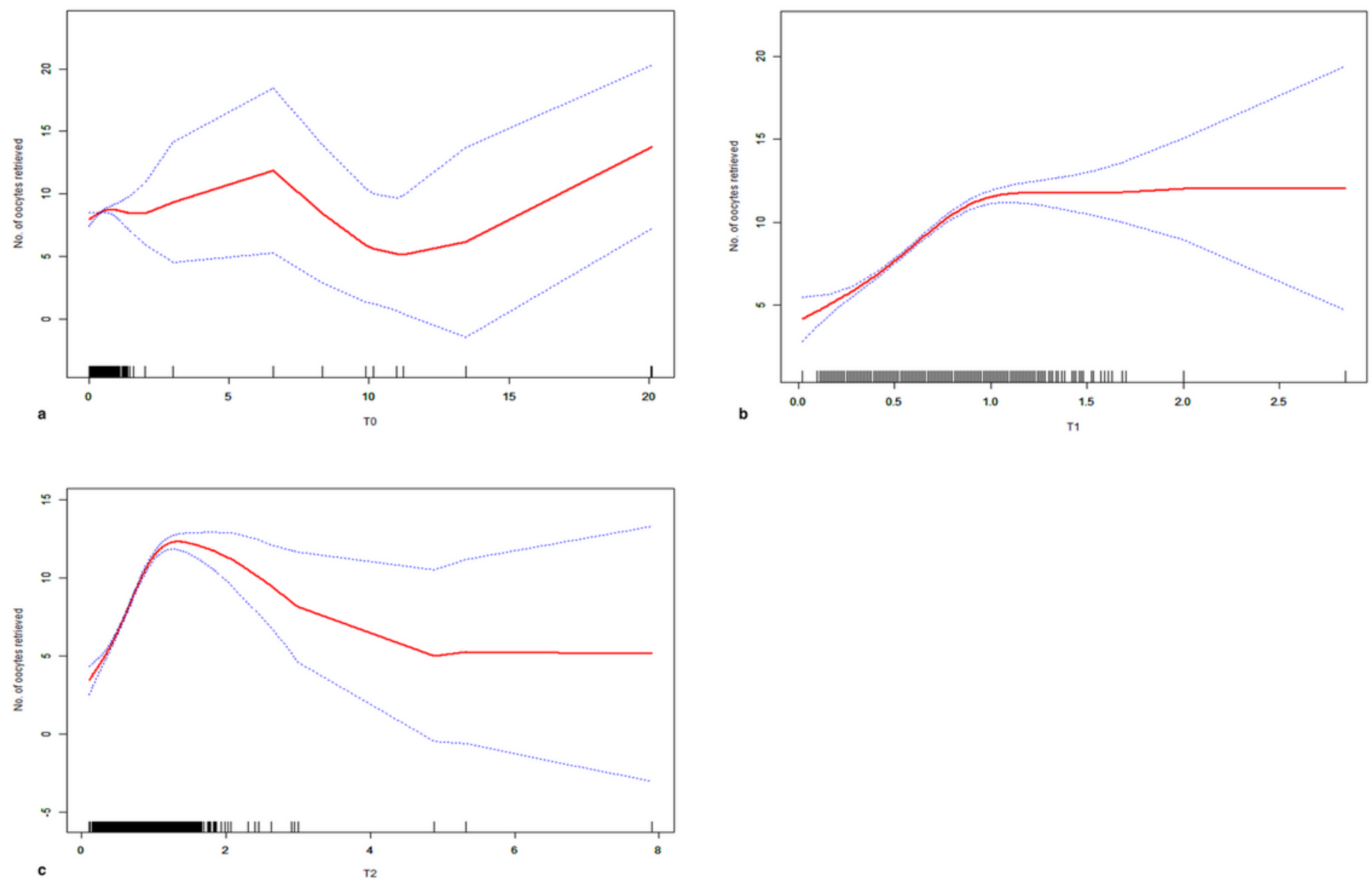

Figure 3

The fitting curves showing the relationship of the testosterone levels and the numbers of oocytes retrieved. (a. T0, B. T1, C. T2) T0: basal levels, T1: T levels on the trigger day, T2: T levels on the next day of the trigger day

\section{Supplementary Files}

This is a list of supplementary files associated with this preprint. Click to download.

- Supplementarymaterials.docx 